\title{
Correlation of Intra-Operative Frozen Section Consultation With the Final Diagnosis At a Tertiary Referral Center in Dhaka.
}

\author{
Khaled A ${ }^{1}$, Agrawal L ${ }^{2}$, Nasir $\mathrm{TA}^{3}$
}

\section{Introduction}

The correlation of intra-operative frozen section diagnosis with the final histopathological diagnosis on permanent sections should form an integral part of quality assurance activities in the surgical pathology laboratory. Few institutes in Bangladesh routinely practice frozen section diagnosis, thus there are very few studies or data available.

Intra-operative frozen section examination has great value as a diagnostic method and usually two categories of errors are responsible for the majority of disagreements, which are most commonly false negative. ${ }^{1}$

Internationally published studies have confirmed the over all accuracy of intra-operative frozen section examination. ${ }^{2,4}$ A study sponsored by college of American pathologist showed a concordance rate of $98.58 \%$. Of the discordant cases $67.8 \%$ were false-negative diagnosis. ${ }^{5}$ In terms of turn around time, a large multi-centered study conducted by CAP showed that $90 \%$ of the frozen section were completed within 20 minutes. $^{6}$

Apollo Hospitals Dhaka, is a tertiary referral 450 bedded hospital has been conducting frozen section for the last 6 years on routine basis. The number of frozen sections has been increasing gradually.

This study was done to determine the frozen section and routine section correlation, causes of discrepancies and turn around time for the cases done in a period of three and half years in this institute.

\section{Materials and Method}

During this study, epidemiological data and pathology slides of 176 cases of frozen sections reported at the histopathology department between $1^{\text {st }}$ January 2008 and $31^{\text {st }}$ May (2011) were reviewed.

Information regarding surgical pathology cases and epidemiological data were retrieved from Hospital Information System (HIS). Cases were categorized by tumor site, indications of frozen section, discordance and concordance status.

The frozen section specimen as per laboratory routine had been evaluated using rapid Hematoxylin and Eosion stains. Frozen sections were cut on a Sandon cryotome machine. Subsequently, for the permanent section, the specimen was fixed overnight in $10 \%$ buffered formalin, grossed and adequate representative sections were taken according to the standardized guidelines.

The number and type of discrepancies were compared including sampling and interpretation errors. We also checked the turn around time by reviewing the records of all cases.

\section{Results}

During the period of three and half years, 176 cases of frozen section were performed. It was among the 9441 surgical pathology cases.

The most common pathological processes encountered were verification and categorization of neoplasm, assessment of tumor margin, confirmation of tissue type and lymph nodes for metastasis. Among these 176 cases, 3 cases were found to be discordant (1.70\%) (Table-1) and (Table-2) 
Table 1:

Frozen sections according to site, number, concordant and discordant cases.

\begin{tabular}{|l|l|l|l|}
\hline Site & Number & Discordant & Concordant \\
\hline & of cases & cases (\%) & cases (\%) \\
\hline Ovary and adnexal mass & 43 & 0 & 43 \\
\hline Breast & 42 & 01 & 41 \\
\hline Thyroid & 18 & 01 & 17 \\
\hline $\begin{array}{l}\text { Head and neck (oral cavity, tongue } \\
\text { larynx, ear, nose, nasopharynx) }\end{array}$ & 15 & 01 & 14 \\
\hline Kidney & 12 & 00 & 12 \\
\hline Surgical margin & 10 & 00 & 10 \\
\hline CNS (Central Nervous System) & 09 & 00 & 09 \\
\hline Soft tissue & 05 & 00 & 05 \\
\hline Ganglion cell & 04 & 00 & 04 \\
\hline Lymph node & 04 & 00 & 04 \\
\hline Bone & 03 & 00 & 03 \\
\hline Stomach & 03 & 00 & 03 \\
\hline Ureter & 03 & 00 & 03 \\
\hline Para-thyroid & 03 & 00 & 03 \\
\hline Testis & 01 & 00 & 01 \\
\hline Endometrium & 01 & 00 & 01 \\
\hline Total & 176 & $03(1.70 \%)$ & $173(98.3 \%)$ \\
\hline
\end{tabular}

Table-2:

Number and percent of discordant cases according to site

\begin{tabular}{|lll|}
\hline Site & Number of cases & Discordant cases (\%) \\
\hline Breast & 42 & $01(2.38 \%)$ \\
\hline Head neck & 15 & $01(6.66 \%)$ \\
\hline Thyroid & 18 & $01(5.55 \%)$ \\
\hline Total & 75 & $03(4 \%)$ \\
\hline
\end{tabular}

Almost all the cases were reported within 20 minutes (turn around time). The sensitivity of frozen section as a diagnostic test was $98.85 \%$ and the positive predictive value was $98.42 \%$.

\section{Discussion}

The accuracy of frozen section diagnosis at the histopathology department of Apollo Hospitals Dhaka is comparable to international quality control statistics for frozen section. The discord tant frequency in our study was $1.7 \%$ and the concordant rate was 98.3\%. As per CAP study,the discordant rate in different laboratories has been in a range of $1 \%$ to $5 \%$. $^{7,8}$ Results from other countries like UK show accuracy of $97.4 \%{ }^{9}$, Japan $96 \%{ }^{10}$ and China $92.6 \%{ }^{11}$

The first discordant case was from head neck region tumor. In frozen section we have reported the tumor as spindle cell tumor (Fig1a), which was latter, proved to be embryonal rhadomyosarcoma in routine sections. 




Figure 1(a): Frozen section show proliferated area of bland spindle shaped cells.

Embryonal rhabdomyosarcoma is composed of round to spindle cells with hyperchromatic nuclei and larger rhabdomyoblasts with eosinophilic cytoplasm (Fig1b). The spindle cell variant, characterized by spindle cells in fascicular to storiform growth pattern can be deceptively bland and difficult to categorize as malignant ${ }^{12}$ which happened in this case. Therefore, in this case, the reason for discrepancy was interpretative.

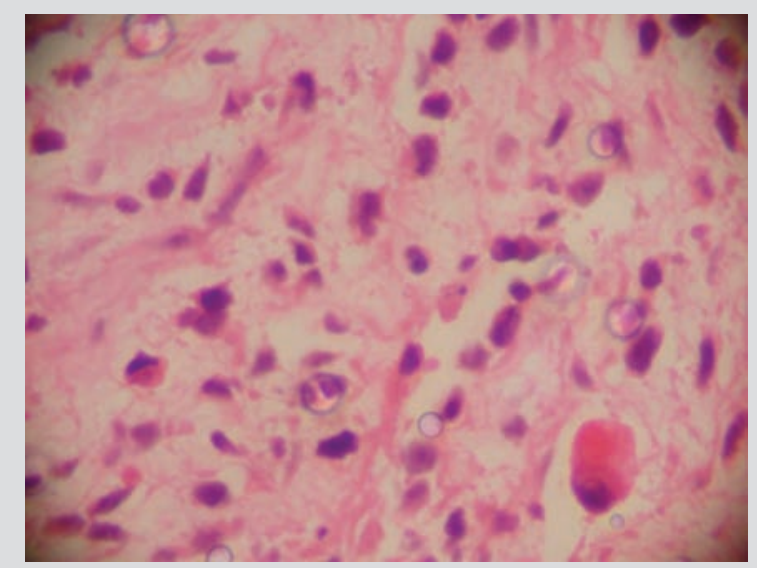

Figure 1(b): Permanent section shows embryonal rhabdomyosarcoma composed of anaplastic round to spindle shaped cells with rhabdomyoblast

The second discordant case was invasive lobular carcinoma of breast, which we failed to confirm as unequivocally as malignant in frozen section. Lobular carcinoma of breast is composed of uniform, round, small to medium sized cells with round and normochromic nuclei expanding the lobules and infiltrating the surrounding stroma as single cell or Indian file pattern accompanied by fibrosis and lymphocytes which may mask the picture of malignancy. ${ }^{3}$ Moreover, if sampling is not done adequately, the infiltrating component can be missing. Due to lack of cellular atypia, necrosis, atypical mitosis and improper sampling area, the discrepancy resulted. In this case, both interpretative and sampling error was responsible for the discrepancy. The third discordant case was from thyroid. In frozen section, it was reported as positive for malignancy. The tumor was composed of mostly hurthle cells with moderate pleomorphism arranged in follicles associated with tumor giant cells. After taking more routine sections from frozen remnants, it shows a well capsulated (2 cm in diameter) hurthle cell neoplasm associated with areas of Hashimoto's thyroiditis and reported as hurthle cell tumour in benign spectrum. The criteria for malignancy in hurthle cell neoplasm is larger size $(>4 \mathrm{~cm})$, capsular and vascular invasion which was absent in this case. In this case, the discrepancy is also both interpretative and sampling.

The average turn around time of frozen section diagnosis in our center was within 15-20 minutes. Almost all the cases, were reported in less than 20 minutes which is comparable with other western studies. ${ }^{6}$

Correlation between frozen section and routine section diagnosis is an important quality parameter for any surgical pathology laboratory. In addition, long tern monitoring of frozen permanent section correlation improves performance. The overall error rates and turn around time of our institute are within the range of international standard. However, improving more accurate interpretation, careful sampling and better communication with clinician can reduce the rate more. 


\section{References}

1. White VA, Trotter MJ. Quality assurance in anatomic pathology: correlation of intra-operative consultation with final diagnosis in 2812 specimens. Abstract presented at the $96^{\text {th }}$ annual meeting of the United States and Canadian Academy of Pathology, 2007.

2. Oneson RH, Minke JA, Silverberg S G. Intra-operative pathologic consultation: an audit of 1000 recent consecutive cases. Am J Surg Pathol. 1989;13:237-43.

3. Howannit PJ, Hoffman GG, Zarbo RJ. The accuracy of frozen section diagnosis in 34 Hospitals. Arch Pathol Lab Med. 1990;114:355-9.

4. Rogers C, Klatt EC, Chandrasoma P. Accuracy of frozen section diagnosis in a teaching hostipital. Arch Pathol Lab Med. 1987;111:355-9.

5. Gephardt GN, Zarbo RJ. Interinstitutional comparison of frozen section consultations: A College of American Pathologists Q-probes study of 90, 538 cases in 461 institutions. Arch pathol Lab Med. 1997;120:804-9.

6. Novis DA, Zarbo RJ. Interinstitutional comparison of frozen section turn around time. A College of American Pathologists Q-probes study of 32868 frozen sections in 700 hospitals. Arch Pathol Lab Med. 1997;121:559-67.
7. Zarbo RJ, Hoffman GG, Howanit PJ. Inter institutional comparison of frozen section consultation. A collage of American Pathologists Q-probe study of 79647 consultation in 297 North American institutions. Arch pathol Lab Med. 1991;115:1187-94.

8. Rwab SS, Tworek JA, Souers R, Zarbo RJ. The value of monitoring frozen section permanent section correlation data over time. Arch Pathol Lab Med. 2006;130:337-42.

9. Lessells AM, Simpson JG. A restrospective analysis of the accuracy of immediate frozen section diagnosis in surgical pathology. Br. J Surg. 1959;63:327-9.

10. IKemura K, Ohya R. The accuracy and usefulness of frozen section diagnosis. Head Neck. 2006;12:298-302.

11. Wen MC, Chen JT. Frozen section diagnosis in surgical pathology. A quality assurance study. Kaohsiung J Med Sci. 1997;13:534-9.

12. Thompson L.B.R, Fanburn-Smith J.C. Malignant soft tissue tumours. In Barnes L, Eveson JW, Reichart P, Sidransky, editiors. Pathology and Genetics of Head and Neck Tumours . Lyon: IARC Press; 2005. p. 38-40.

13. Juan R.Rosai and Ackermans Surgical pathology, 10th edition. New York:Mosby-Elsevier; 2011. p. 1694-1709. 